\title{
Expression and mutation analysis of the discoidin domain receptors I and 2 in non-small cell lung carcinoma
}

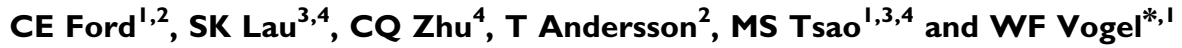 \\ 'Department of Laboratory Medicine and Pathobiology, Faculty of Medicine, University of Toronto, Toronto, Ontario, Canada; ${ }^{2}$ Division of Experimental \\ Pathology, Department of Laboratory Medicine, Lund University, University Hospital Malmö, Malmö, Sweden; ${ }^{3}$ Department of Medical Biophysics, \\ University of Toronto, Toronto, Ontario, Canada; ${ }^{4}$ University Health Network, Ontario Cancer Institute and Princess Margaret Hospital, Toronto, Ontario, \\ Canada
}

The discoidin domain receptors, (DDR)I and DDR2, have been linked to numerous human cancers. We sought to determine expression levels of DDRs in human lung cancer, investigate prognostic determinates, and determine the prevalence of recently reported mutations in these receptor tyrosine kinases. Tumour samples from 146 non-small cell lung carcinoma (NSCLC) patients were analysed for relative expression of DDRI and DDR2 using quantitative real-time PCR (qRT-PCR). An additional 23 matched tumour and normal tissues were tested for differential expression of DDRI and DDR2, and previously reported somatic mutations. Discoidin domain receptor I was found to be significantly upregulated by 2.15 -fold $(P=0.0005)$ and DDR2 significantly downregulated to an equivalent extent $(P=0.000 \mathrm{I})$ in tumour vs normal lung tissue. Discoidin domain receptor 2 expression was not predictive for patient survival; however, DDRI expression was significantly associated with overall (hazard ratio (HR) $0.43,95 \%$ $\mathrm{Cl}=0.22-0.83, P=0.014)$ and disease-free survival $(\mathrm{HR}=0.56,95 \% \mathrm{Cl}=0.33-0.94, P=0.029)$. Multivariate analysis revealed DDRI is an independent favourable predictor for prognosis independent of tumour differentiation, stage, histology, and patient age. However, contrary to previous work, we did not observe DDR mutations. We conclude that whereas altered expression of DDRs may contribute to malignant progression of NSCLC, it is unlikely that this results from mutations in the DDRI and DDR2 genes that we investigated.

British Journal of Cancer (2007) 96, 808-8I4. doi:10.1038/sj.bjc.66036I4 www.bjcancer.com

Published online 13 February 2007

(c) 2007 Cancer Research UK

Keywords: lung cancer; DDRI; DDR2; mutation

Lung cancer is the leading cause of cancer-associated deaths worldwide and has one of the poorest prognoses among all cancer types. Non-small cell lung carcinoma (NSCLC) comprises approximately $80 \%$ of lung cancer, and its overall 5 -year survival rate is $15 \%$. Early stage tumours are treated primarily by complete surgical resection, yet $30-55 \%$ of patients will develop recurrence and die of the disease. Despite significant advances achieved in the chemotherapy and radiation therapy for advanced disease patients, most patients will eventually develop resistance. Thus, there is a need for novel and effective targeted therapies, the development of which requires our greater understanding of the genetic abnormalities in lung cancers.

As the complexity and unique nature of individual human cancers become apparent, the analysis of individual patients' genetic makeup has become important in guiding the development of novel treatments. A striking example of this has recently emerged in therapies using the epidermal growth factor receptor (EGFR) small molecule inhibitors (Shepherd et al, 2005; Tsao et al,

\footnotetext{
*Correspondence: Dr WF Vogel, Medical Sciences Building, Room 6342, I King's College Circle, Toronto, Ontario M5S IA8 Canada; E-mail: w.vogel@utoronto.ca

Received 16 October 2006; revised 4 January 2007; accepted 9 January 2007; published online 13 February 2007
}

2005; Blackhall et al, 2006). Somatic mutations in the tyrosine kinase domain and copy number changes of the EGFR gene play critical roles in determining the sensitivity and clinical benefit of NSCLC patients treated by EGFR inhibitor drugs.

The discoidin domain receptors (DDRs) are receptor tyrosine kinases (RTKs) belonging to the same enzyme family as EGFR. The DDR1 gene is divided into 19 exons and has a coding sequence of $2742 \mathrm{bp}$. Discoidin domain receptor 2 is also divided into 19 exons and encodes a $2568 \mathrm{bp}$ mRNA. Discoidin domain receptor 1 and DDR2 share similar structures, consisting of a characteristic discoidin homology domain, stalk region, transmembrane region, juxtamembrane region, and kinase domain. Compared to other RTKs, DDRs are unique because they have native collagens as their ligands. Discoidin domain receptors have been shown to exhibit altered expression patterns in multiple human cancers, including breast, oesophageal, ovarian, brain and lung tumours (Vogel et al, 2006). Of note, DDR1 appears to be preferentially expressed in tumour cells, whereas DDR2 is expressed in tumour stroma (Alves et al, 1995). The mechanism by which these receptors may contribute to oncogenesis is as yet unknown; however, given their important role in transmitting signals from the extracellular matrix (ECM), it is possible that they act as regulators of cell proliferation, adhesion, migration, and subsequent tumour metastasis. Similar to EGFR it is conceivable that altered expression and/or mutation of DDRs trigger abnormal activity, ultimately leading to enhanced 
proliferation and oncogenic transformation. The mutations in EGFR are all found within the catalytic kinase domain, and mostly consist of single-point mutations or small deletions (Sakurada et al, 2006; Shigematsu and Gazdar, 2006). In a related study, Davies et al (2005) screened for mutations in lung cancer by comprehensively sequencing all 518 kinases in the human genome. Among mutations in several other RTKs, the authors also described novel somatic mutations in DDRs, specifically the mutations A496S and R824W for DDR1 and the mutation R105S for DDR2.

Here, we sought to extensively explore the association of DDRs with human lung cancer by determining their expression levels and the prevalence of the newly reported mutations in a larger cohort of NSCLC primary tumours and tumour cell lines. We demonstrated a significant upregulation of DDR1 and a downregulation of DDR2 in lung tumour tissue compared with matched normal tissues from the same patients; importantly we demonstrated that DDR1 expression was a good prognostic marker for early-stage NSCLC patients. However, we did not identify any of the three previously identified mutations in our cohort of lung cancers or in any of the cell lines tested.

\section{MATERIALS AND METHODS}

\section{Patients}

A total of 146 primary lung tumours and an independent set of 23 matched tumour and normal lung tissue samples were harvested from NSCLC patients treated by surgical resection without adjuvant chemotherapy at the University Health Network and Mount Sinai Hospital, Toronto, Canada (Table 1A). Tissues were harvested within $30 \mathrm{~min}$ after complete resection, and the quality and pathology of tumour tissue was confirmed by the study pathologist (M-ST). Samples with a tumour-cell content of at least $50 \%$ were used in the study. The University Health Network Research Ethics Board has approved the use of these samples and their associated clinical information in this study.

\section{Cell lines and xenograft models}

Human cell lines (ATCC) were cultured and grown in media according to the manufacturer's recommended conditions (Table 2). A lung xenograft model had been generated previously and no additional animal experiments were necessary for the current work (Liu and Tsao, 1993). Briefly, $2 \times 10^{6}$ cells in $70 \mu \mathrm{l}$ medium (RPMI-1640, 10\% fetal bovine serum) containing $10 \%$ Matrigel (BD Bioscience, San Jose, CA, USA) were subcutaneously injected into the ventral abdomen of 5-week-old male severe combined immunodeficiency mice (Table 2). Formation of tumours was observed by palpation, and growth measured twice a week until the tumour reached a volume of $1 \mathrm{~cm}^{3}$. After mice were killed, tumour tissue was harvested and snap-frozen in liquid nitrogen. All animals received humane care in compliance with the Guide to the Care and Use of Experimental Animals issued by the Canadian Council of Animal Care. All animal procedures were performed in accordance with a protocol approved by the animal care committee of the University of Toronto.

\section{RNA extraction}

Ribonucleic acid was extracted from patient samples and cell lines using the method of Chomczynski and Sacchi (1987); extracts were purified using the RNeasy kit (Qiagen, Hilden, Netherlands), DNase treated (Ambion, Austin, TX, USA), and quantified via spectrophotometry. Ribonucleic acid quality was assessed by agarose gel electrophoresis.

Table IA Comparative clinical and pathological features of the full cohort of NSCLC patients. Patients were dichotomised using the median level of DDRI expression, whereas patients with undetectable DDR2 were considered low expressors

\begin{tabular}{|c|c|c|c|}
\hline & All patients (146) & Elevated DDRI expression (73) & Reduced or absent DDR2 expression (104) \\
\hline Adenocarcinoma & $92(63 \%)$ & $39(53 \%)$ & $63(61 \%)$ \\
\hline Squamous cell carcinoma & $54(37 \%)$ & $34(47 \%)$ & $41(39 \%)$ \\
\hline \multicolumn{4}{|l|}{ Pathological stage } \\
\hline Stage I & $95(65 \%)$ & $5 \mathrm{I}(70 \%)$ & $62(60 \%)$ \\
\hline Stage ॥ & $34(23 \%)$ & $15(21 \%)$ & $30(29 \%)$ \\
\hline \multicolumn{4}{|l|}{ T stage } \\
\hline $\mathrm{TI}$ & $45(31 \%)$ & $28(38 \%)$ & $30(29 \%)$ \\
\hline $\mathrm{T} 2$ & $92(63 \%)$ & $43(59 \%)$ & $68(65 \%)$ \\
\hline T3 & $9(6 \%)$ & $2(3 \%)$ & $6(6 \%)$ \\
\hline \multicolumn{4}{|l|}{$N$ stage } \\
\hline No & $94(64 \%)$ & $5 \mathrm{I}(70 \%)$ & 65 (63\%) \\
\hline \multicolumn{4}{|l|}{ Differentiation } \\
\hline MD & 39 (27\%) & $21(29 \%)$ & $29(28 \%)$ \\
\hline PD & $37(25 \%)$ & $16(22 \%)$ & $30(29 \%)$ \\
\hline$\cup$ & $37(25 \%)$ & $18(24 \%)$ & $24(23 \%)$ \\
\hline \multicolumn{4}{|l|}{ Sex } \\
\hline Male & $63(43 \%)$ & $32(44 \%)$ & $47(45 \%)$ \\
\hline Female & $83(57 \%)$ & $4 \mathrm{l}(56 \%)$ & 57 (55\%) \\
\hline Median Survival time (years) & 3.89 & 4.98 & 4.29 \\
\hline
\end{tabular}

$\mathrm{MD}=$ moderately differentiated; $\mathrm{PD}=$ poorly differentiated; $\mathrm{WD}=$ well differentiated; $U=$ unknown. 
Table IB Cohort of matched tumour and normal lung tissues with relative DDRI and DDR2 expression levels. Expression values were calculated relative to that of four normalizer genes

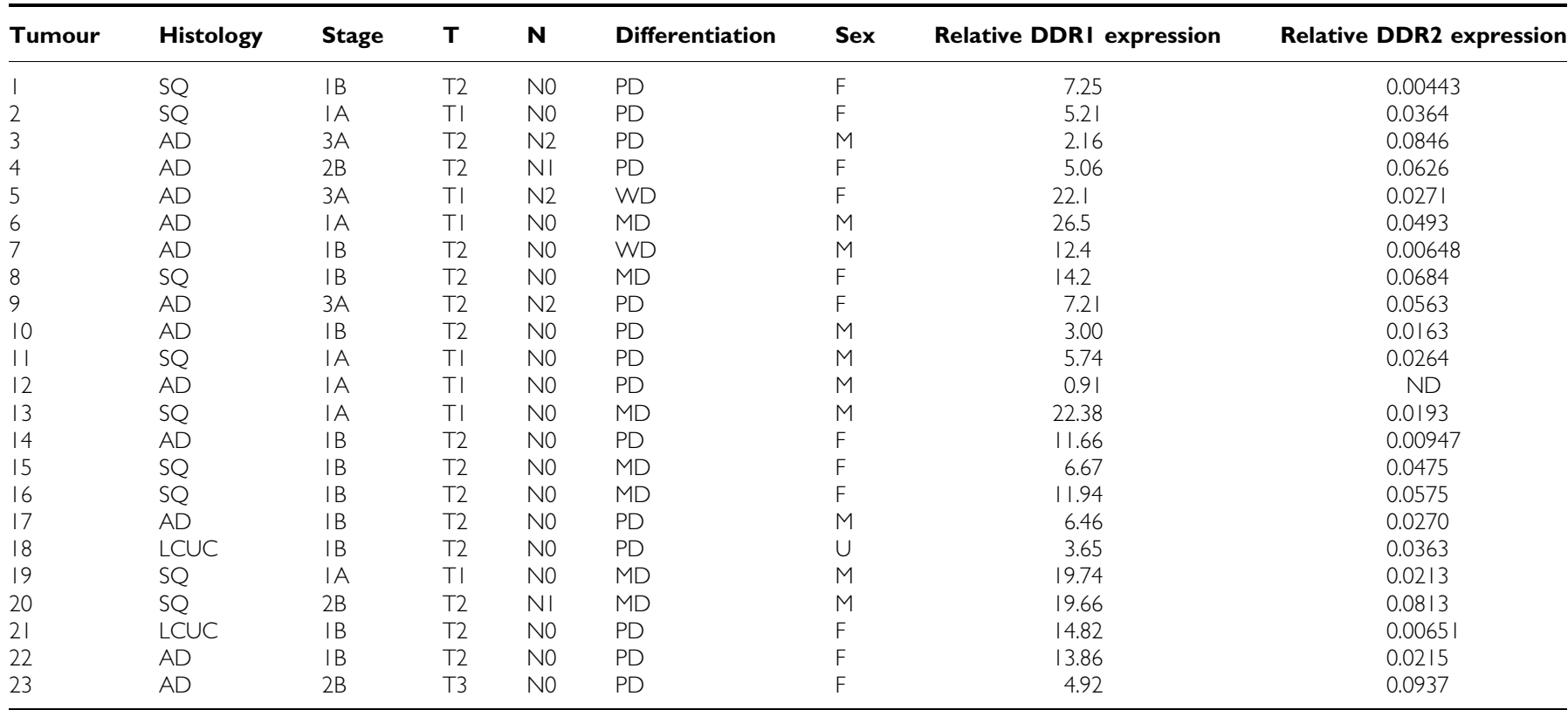

$\mathrm{AD}=$ adenocarcinoma; $\mathrm{DDR}$ I = discoidin domain receptor $1 ; \mathrm{DDR} 2=$ discoidin domain receptor 2 ; $L C U C=$ large cell undifferentiated carcinoma; $M D=$ moderately differentiated; $\mathrm{ND}=$ expression level below detection limit; $\mathrm{PD}=$ poorly differentiated; $\mathrm{SQ}=$ squamous cell carcinoma; $\mathrm{U}=$ data not available; $\mathrm{U}=$ status unknown; $\mathrm{WD}=$ well differentiated.

\section{Quantification and analysis of DDR expression in lung tumour samples}

Quantitative real-time PCR (qRT-PCR) was conducted using the SYBR Green assay in the ABI PRISM 7900-HT (Applied Biosystems, Foster city, CA, USA). Each $10 \mu \mathrm{l}$ qRT-PCR aliquet contained a $2 \mathrm{ng}$ equivalent of cDNA in a 384-well plate. The reactions were activated at $95^{\circ} \mathrm{C}$ for 3 min followed by 40 cycles of $95^{\circ} \mathrm{C}(15 \mathrm{~s}), 65^{\circ} \mathrm{C}(15 \mathrm{~s})$ and $72^{\circ} \mathrm{C}(20 \mathrm{~s})$. The amount of transcript per ng cDNA was calculated using standard curves generated using a pool of genomic DNA from 10 normal lung tissue samples as described (Yun et al, 2006). Primer sequences were designed with Primer Express v 2.0 (Applied Biosystems). Primer sequences for DDR1 were forward primer ATGGAGCAACCACAGCTTCTC, reverse primer CTCAGCCGGTCAAACTCAAACT, and for DDR2, forward primer GGAGGTCATGGCATCGAGTT, reverse primer GAGTGCCATCCCGACTGTAATT. Technical replicates displayed high correlation $\left(R_{\mathrm{avg}}=0.95 \pm 0.03\right)$ and were collapsed by averaging. Expression values were then $\log _{2}$-transformed. Standardisation and normalisation were conducted using the geometric mean of the expression levels of four normaliser genes (ACTB, forward primer TCCTAAAAGCCACCCCACTTCT, reverse primer GGGAGAGGACTGGGCCATT, TBP, forward primer GGGCATT ATTTGTGCACTGAGA, reverse primer TAGCAGCACGGTATGA GCAACT, BAT1, forward primer CGGTATCAGCAGTTTAAAG ATTTTCA, reverse primer TGCCTCGGCCAAATAGGTT, and B2M, forward primer GAGTGCTGTCTCCATGTTTGATGT, reverse primer AAGTTGCCAGCCCTCCTAGAG). An indepth description of this method was published recently (Barsyte-Lovejoy et al, 2006).

\section{PCR and sequencing analysis}

Total RNA was transcribed into cDNA using Superscript II Reverse Transcriptase and oligo-dT (Invitrogen, Carlsbad, CA, USA). Primers were designed to amplify the regions containing previously identified DDR mutations in the juxtamembrane (forward primer GAGCTGACGGTTCACCTCTC, reverse primer AATGTCAGCCTCGGCATAAT), and kinase domains (forward primer GGTGCTGATGCTCTGTAGGG, reverse primer CGTGT TGAGTGCATCCTCTG) of DDR1 and the discoidin domain of DDR2 (forward primer GACTTGCACACCCTCCATTT, reverse primer GAGTGGTCGGTGACTGGAAT). The housekeeping gene, glyceraldehyde-3-phosphate dehydrogenase (forward primer CAATGACCCCTTCATTGACC, reverse primer TGCTGTAGCCA AATTCGTTG), was used as a control. cDNA was subjected to PCR amplification consisting of an initial 2 min denaturation at $94^{\circ} \mathrm{C}$, followed by 35 cycles of amplification $\left(94^{\circ} \mathrm{C}, 30 \mathrm{~s} ; 57^{\circ} \mathrm{C}, 30 \mathrm{~s} ; 72^{\circ} \mathrm{C}\right.$, $45 \mathrm{~s}$ ), and a final extension at $72^{\circ} \mathrm{C}$ for $3 \mathrm{~min}$. Polymerase chain reaction products were subjected to agarose gel electrophoresis with appropriate size markers, and samples producing bands of the correct size were purified using the MiniElute PCR Purification kit (Qiagen). Purified samples were sequenced at The Centre for Applied Genomics (TCAG) facility in Toronto, Canada, using an ABI3730XL DNA sequencer. Samples were sequenced in both directions using the same primers as for amplification, and sequences aligned and analysed using ChromasPro software (Technelysium, Tewantin, Australia). Samples that gave ambiguous sequences were repeated up to three times. Two samples were excluded from the study as clean sequences could not be generated.

\section{Genomic sequencing}

Additionally, DNA was extracted from all 12 lung cancer cell lines using standard techniques. Polymerase chain reaction was performed using exon-specific primers spanning putative mutation sites in DDR1 and DDR2, and PCR product sequenced as outlined above.

\section{Statistical analysis}

Matched $t$-tests were used to determine differential expression of DDR1 and DDR2. The Spearman's correlation, Kruskal-Wallis, 
and Wilcoxon test were used to assess association within and between molecular indices and the pathological or clinical factors. The end points for analyses were overall survival (from date of surgery to date of death) and disease-free survival (from date of surgery to date of disease recurrence). The Cox proportional hazards model was used to test the association of survival and DDR1 expression, where DDR1 expression was treated as a continuous variable. For Kaplan-Meier and multivariate analysis, subjects were dichotomised according to the median expression levels of DDR1 (median=32.6); low DDR1 expressors are defined as patients with expression levels below the median, whereas high DDR1 expressors are those with expression values above the median. Discoidin domain receptor 2 cases were dichotomised based on expressors vs nonexpressors. The Cox proportional hazards model was employed for the multivariate analysis. All statistical analysis was conducted using SAS software (v9.1).

\section{RESULTS}

Quantitative real-time PCR analysis of DDR1 and DDR2 expression performed on the 146 NSCLC tumour samples (full data set available as Supplementary Table S1) showed neither DDR1 nor DDR2 were associated with factors such as tumour stage $(P=0.38$ and $P=0.51$, respectively), differentiation $(P=0.93$ and $P=0.60$, respectively), and age (Spearman's correlation $P=0.82$ and $P=0.48$, respectively). Normalised DDR1 expression ranged from 0 to 1184 transcript copies per $2 \mathrm{ng}$ of cDNA, whereas DDR2 expression ranged from 0 to 186 copies. The expression of DDR1 was significantly higher in squamous cell carcinoma than in adenocarcinoma $(P=0.007$; median expression 40.6 vs 23.1, respectively). In contrast to DDR2 whose expression level was not prognostic (Supplementary Table S2), high expression of
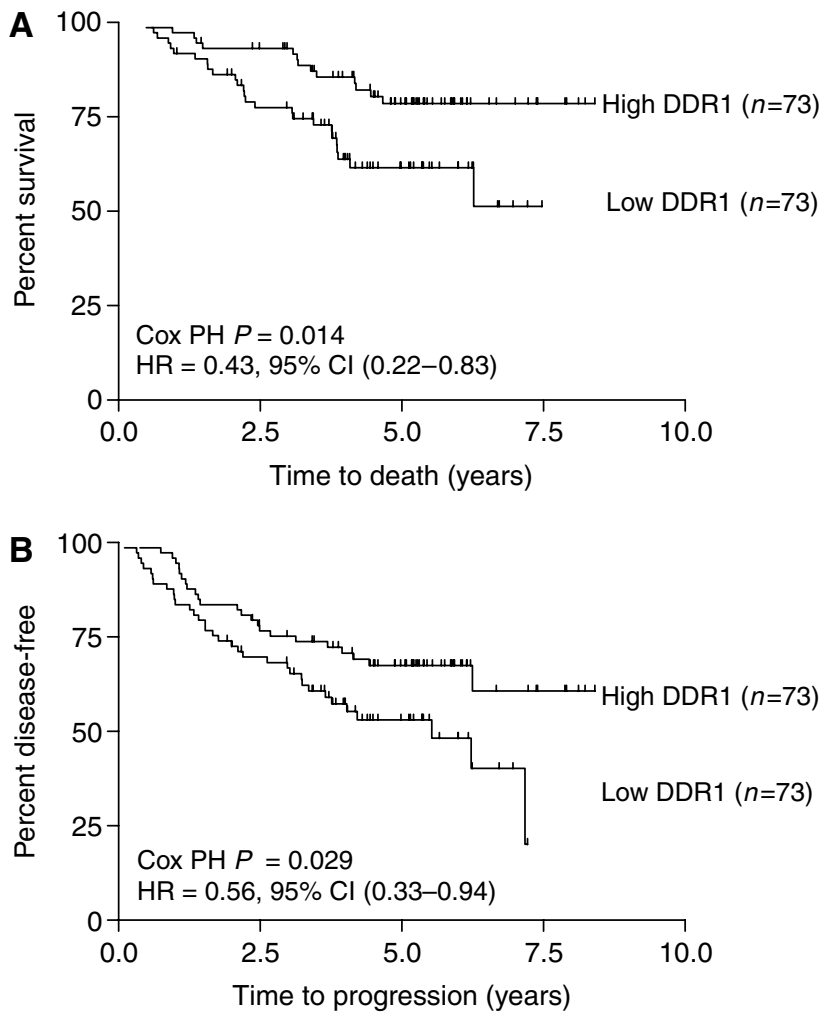

Figure I Kaplan-Meier analysis of (A) overall survival and (B) diseasefree survival, according to DDRI expression levels. Patients were dichotomised based on the median level of DDRI expression.
DDR1 was associated with significantly favourable overall survival in this cohort of patients $(\mathrm{HR}=0.43,95 \% \mathrm{CI}=0.22-0.83$, $P=0.014$ ) (Figure 1A). Discoidin domain receptor 1 expression was also significantly associated with greater disease-free survival ( $\mathrm{HR}=0.56,95 \% \mathrm{CI}=0.33-0.94, P=0.029)$ (Figure 1B). In multivariate analysis, DDR1 expression remained significant in predicting overall survival $(\mathrm{HR}=0.5,95 \% \mathrm{CI}=0.26-0.97$, $P=0.04$ ), but not disease-free survival, after adjustments for stage, differentiation, histology, and age.

Next, we analysed a cohort of 23 samples from lung cancer patients, which included matched normal tissue for each tumour sample. Discoidin domain receptor 1 was shown to be upregulated by 2.15 -fold $(P=0.0005)$, and DDR2 downregulated by an equivalent amount $(1.94$-fold, $P=0.0001)$ in tumour tissue compared with matched normal samples (Table 1B, Figure 2). We then analysed the genetic sequences of DDR1 and DDR2 in this cohort. To our surprise, we failed to detect any of the previously identified mutations in DDR1 and DDR2, nor any new mutations (Davies et al, 2005). We then subjected 12 lung cell lines, six lung xenografts, and 15 other cell lines to sequence analysis. The 12 lung cell lines were also subjected to genomic sequencing. Again, none of the previously reported mutations was found. This group included the lung cell line NCI-H1770 that had previously been reported to harbour the $\mathrm{R} 824 \mathrm{~W}$ mutation in the DDR1 kinase

Table 2 List of cell lines and xenografts used for sequence analysis

\begin{tabular}{|c|c|}
\hline Name & Pathology \\
\hline \multicolumn{2}{|l|}{ Lung cell lines } \\
\hline A549 & AD \\
\hline $\mathrm{HI} 25$ & ADSQ \\
\hline $\mathrm{H} 1264$ & SQ \\
\hline $\mathrm{HI} 57$ & SQ \\
\hline $\mathrm{H} 226$ & SQ \\
\hline H358 & BAC \\
\hline $\mathrm{H} 460$ & LCC \\
\hline H520 & SQ \\
\hline $\mathrm{H} 66 \mathrm{I}$ & LCC \\
\hline $\mathrm{HII} 84$ & SQ \\
\hline $\mathrm{NCl}-\mathrm{HI} 770$ & NE \\
\hline RVH6849 & $A D$ \\
\hline \multicolumn{2}{|l|}{ Lung xenografts } \\
\hline $\mathrm{MGH} 4$ & LCC \\
\hline $\mathrm{MGH} 7$ & SQ \\
\hline MGH8 & $A D$ \\
\hline MGHI3 & $A D$ \\
\hline MGH24 & $A D$ \\
\hline $\mathrm{MGH} 30$ & ADSQ \\
\hline \multicolumn{2}{|l|}{ Other cell lines } \\
\hline NTERA2 & Testicular cancer \\
\hline HTB।26 & Breast \\
\hline HepG2 & Hepatoblastoma \\
\hline HTI080 & Fibrosarcoma \\
\hline SW872 & Liposarcoma \\
\hline T47D & Breast carcinoma \\
\hline MCF7 & Breast carcinoma \\
\hline MCFI2A & Breast \\
\hline Colo205 & Colon carcinoma \\
\hline MOLT-4 & Leukaemia \\
\hline SKOV3 & Ovarian adenocarcinoma \\
\hline SKMEL28 & Melanoma \\
\hline MCFIOA & Breast \\
\hline HEK293 & Kidney \\
\hline MDAMB23I & Breast carcinoma \\
\hline
\end{tabular}

$\overline{A D}=$ adenocarcinoma; $\mathrm{ADSQ}=$ adenosquamous carcinoma; $\mathrm{BAC}=$ bronchoalveolar carcinoma; $L C C=$ large cell carcinoma; $S Q=$ squamous cell carcinoma; $\mathrm{NE}=$ neuroendocrine tumour. 


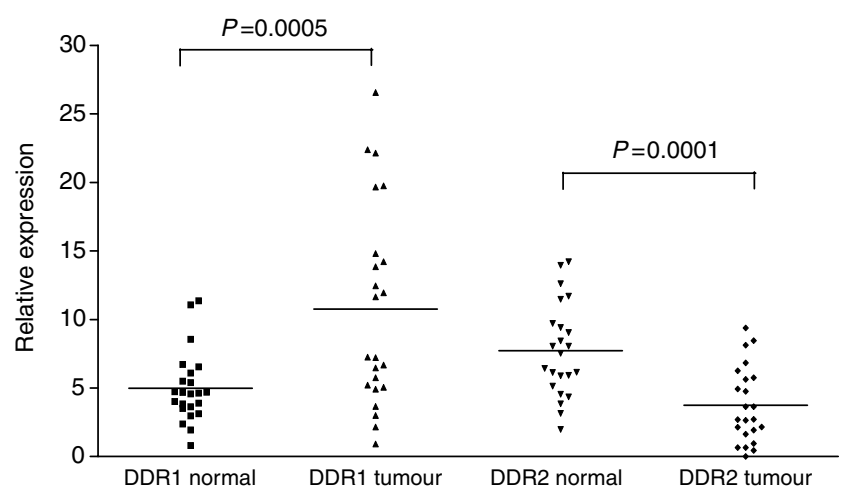

Figure 2 Accumulated plot of DDR qRT-PCR data demonstrating relative expression of DDRI and DDR2 in normal and cancerous tissues from lung cancer patients. Discoidin domain receptor I was found to be significantly upregulated by 2.15 -fold $(P=0.0005)$ and DDR2 significantly downregulated by an equivalent amount $(P=0.000 \mathrm{I})$ in tumour tissue compared with normal tissue from lung cancer patients. Expression values were calculated relative to that of four normaliser genes.

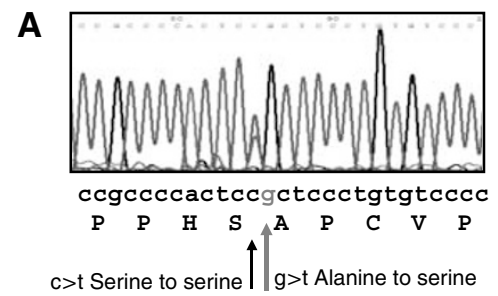

\begin{tabular}{|l|c|c|c|c|}
\hline \multicolumn{2}{l|}{} & \multicolumn{2}{l|}{ DDR1 } & DDR2 mutations \\
& mutations/polymorphisms & \\
\hline Mutation location & A496S & S495S & $R 824 W$ & $R 105 S$ \\
\hline $\begin{array}{l}\text { Clinical lung tumour } \\
\text { tissue }\end{array}$ & $0 / 23$ & $15 / 23$ & $0 / 23$ & $0 / 23$ \\
\hline Clinical lung normal tissue & $0 / 23$ & $6 / 23$ & $0 / 23$ & $0 / 23$ \\
\hline Lung cancer cell lines & $0 / 12$ & $1 / 12$ & $0 / 12$ & $0 / 12$ \\
\hline Lung cancer xenografts & $0 / 6$ & $0 / 6$ & $0 / 6$ & $0 / 6$ \\
\hline Other cell lines & $0 / 15$ & $0 / 15$ & $0 / 15$ & $0 / 15$ \\
\hline Total & $0 / 79$ & $22 / 79$ & $0 / 79$ & $0 / 79$ \\
\hline
\end{tabular}

Figure 3 Results of sequence analyses. (A) Location of S495S synonymous change adjacent to A496S somatic mutation identified previously. (B) Overall prevalence of DDRI mutations in clinical lung cohort and cell lines. Six patients had the S485S polymorphism in both their normal and tumour tissue.

domain (Davies et al, 2005) (Figure 3A). We did not detect this mutation in either DNA or RNA sequences from this cell line. Sequences were generated for almost $20 \%$ of the coding sequence of DDR1, and $10 \%$ of DDR2.

Previously identified polymorphisms located in these regions were successfully identified, confirming the robust nature and specificity of the sequencing method employed. One previously identified polymorphism in DDR1, located at amino acid 495, was identified in $46 \%$ of the clinical samples screened. This polymorphism is directly adjacent to the DDR1 A496S mutation identified by Davies et al (2005) that was not identified in any sample of our cohort (Figure 3B). This polymorphism is a synonymous change, and is therefore unlikely to be of functional importance; however, it is of interest to note that whereas six of 23 samples harboured this change in both their normal and tumour tissues suggestive of a germline polymorphism, another nine samples recorded the change only in their tumour tissue, indicating an acquired or somatic aetiology.

\section{DISCUSSION}

We have demonstrated for the first time that the expression of DDRs is significantly deregulated in NSCLC. Furthermore we have shown that DDR1 is an independent favourable prognostic marker for early-stage NSCLC patients, and that mutations in DDR1 and DDR2 appear less frequently than previously reported. The collagen-binding RTKs, DDR1 and DDR2, have previously been linked to various human diseases including fibrosis (Alves et al, 1995; Mao et al, 2002; Lee et al, 2004; Avivi-Green et al, 2006), atherosclerosis (Hou et al, 2001; Hou et al, 2002; Ferri et al, 2004), and cancer (Johnson et al, 1993; Alves et al, 1995; Barker et al, 1995; Nemoto et al, 1997; Weiner et al, 2000; Dejmek et al, 2003; Ongusaha et al, 2003; Heinzelmann-Schwarz et al, 2004; Ram et al, 2006; Vogel et al, 2006). The mechanism by which DDRs may contribute to oncogenesis is as yet unknown.

Although DDR1 has been previously discussed in the context of idiopathic pulmonary fibrosis and inflammation of the lung (Avivi-Green et al, 2006; Matsuyama et al, 2006a, b), a direct link with lung tumorigenesis has not yet been established. In addition, DDR2 has not yet been investigated in the context of lung cancer. This therefore represents the first study to extensively explore and quantify the expression levels of these unique RTKs in a large clinical cohort of lung cancer patients. Discoidin domain receptor 1 was shown to be upregulated in tumour $v s$ normal tissue, whereas DDR2 was downregulated. Intriguingly, our data suggest that higher DDR1 expression can also be a strong independent prognostic indicator for early-stage NSCLC patients. Although DDR2 also appeared to be protective in our cohort, there were ultimately too few cases with quality expression data to make a firm conclusion. These results detailing differences in expression at the mRNA level are also of interest in relation to previous reports that DDR1 exhibits preferential protein expression in tumour epithelial cells, whereas DDR2 is more commonly expressed in the surrounding stroma (Alves et al, 1995). At this stage, it remains unknown as to the mechanisms by which DDRs may contribute to oncogenesis.

We were interested to note the recent study reporting for the first time somatic mutations in DDR1 and DDR2 (Davies et al, 2005). The authors report mutations in two patient samples (one squamous cell carcinoma and one large cell carcinoma), and one lung cancer cell line (NCI-H1770). However, we could not confirm the existence of the DDR1 mutation in the NCI-H1770 neuroendocrine cell line, which we obtained from ATCC and passaged for three times only. Despite repeated amplification, sequencing and analysis of both forward and reverse sequences, the wild-type DDR1 sequence was observed consistently. Davies et al (2005) comment on the unusually large number of mutations in the NCIH1770 cell line cultured in their laboratory and suggest that this may be indicative of a defect in DNA repair that mimics UV exposure. The apparent discrepancy between the two sets of results may also be owing to differences in clonal strains of the NCIH1770 cell lines, and passage number at the time of sequence analysis. Furthermore, we amplified and sequenced 33 cell lines (including 12 lung cell lines and six xenografts) and 46 clinical samples (RNA extracted from 23 matched lung tumour and normal tissue) from patients treated at our institution and did not identify any of the three mutations reported by Davies et al (2005).

Several explanations exist for this disparity. Lung cancer encompasses a broad range of clinical subtypes, and the makeup of the two cohorts differed. We cannot conclude that differences were owing to our methodology as our PCR and sequencing 
methods were robust and results repeatable. Further to this point, we managed to detect both germline and acquired polymorphisms in our samples, thereby verifying our ability to detect mutations if they existed in our population. One synonymous nucleotide change in DDR1 was present in almost half of our clinical cohort. This polymorphism is located at amino acid 495, directly adjacent to amino acid 496, previously identified as the site of a somatic mutation in DDR1. The nucleotide change is a cytosine to a thymine change located at the third nucleotide of the codon, resulting in no alteration in the amino acid serine. The previously identified A496S mutation results from a change from a guanine to a thymine (Davies et al, 2005). The two altered thymine nucleotides are sequential, suggesting that this region of the DDR1 genome may be a hotspot for genetic variation (Glover et al, 2005). We must therefore conclude that if these recently reported DDR1 and DDR2 mutations are valid, then their prevalence must be much lower in the general lung cancer population than expected. This does not however rule out the possibility that they are important mutations contributing clinically to a subset of lung cancers in certain populations. This is analogous to the emerging understanding of the role of EGFR mutations in various populations. As we understand more about the role of RTKs in cancer, it has become important to investigate the presence and prevalence of mutations in these genes, in varied populations. We suggest further research into the presence of mutations in diverse cohorts from varied populations.

\section{REFERENCES}

Alves F, Vogel W, Mossie K, Millauer B, Hofler H, Ullrich A (1995) Distinct structural characteristics of discoidin I subfamily receptor tyrosine kinases and complementary expression in human cancer. Oncogene 10: $609-618$

Avivi-Green C, Singal M, Vogel WF (2006) Discoidin Domain Receptor 1 Deficient Mice are Resistant to Bleomycin-induced Lung Fibrosis. Am J Respir Crit Care Med 174: 420-427

Barker KT, Martindale JE, Mitchell PJ, Kamalati T, Page MJ, Phippard DJ, Dale TC, Gusterson BA, Crompton MR (1995) Expression patterns of the novel receptor-like tyrosine kinase, DDR, in human breast tumours. Oncogene 10: $569-575$

Barsyte-Lovejoy D, Lau SK, Boutros PC, Khosravi F, Jurisica I, Andrulis I et.al. (2006) The c-Myc Oncogene Directly Induces the H19 Noncoding RNA by Allele-Specific Binding to Potentiate Tumorigenesis. Cancer Res 66: $5330-5337$

Blackhall F, Ranson M, Thatcher N (2006) Where next for gefitinib in patients with lung cancer? Lancet Oncol 7: 499-507

Chomczynski P, Sacchi N (1987) Single-step method of RNA isolation by acid guanidinium thiocyanate-phenol-cholroform extraction. Anal Biochem 162: 156-159

Davies H, Hunter C, Smith R, Stephens P, Greenman C, Bignell G, Teague J, Butler A, Edkins S, Stevens C, Parker A, O'Meara S, Avis T, Barthorpe S, Brackenbury L, Buck G, Clements J, Cole J, Dicks E, Edwards K, Forbes S, Gorton M, Gray K, Halliday K, Harrison R, Hills K, Hinton J, Jones D, Kosmidou V, Laman R, Lugg R, Menzies A, Perry J, Petty R, Raine K, Shepherd R, Small A, Solomon H, Stephens Y, Tofts C, Varian J, Webb A, West S, Widaa S, Yates A, Brasseur F, Cooper CS, Flanagan AM, Green A, Knowles M, Leung SY, Looijenga LH, Malkowicz B, Pierotti MA, Teh BT, Yuen ST, Lakhani SR, Easton DF, Weber BL, Goldstraw P, Nicholson AG, Wooster R, Stratton MR, Futreal PA (2005) Somatic mutations of the protein kinase gene family in human lung cancer. Cancer Res 65: 75917595

Dejmek J, Dib K, Jonsson M, Andersson T (2003) Wnt-5a and G-protein signaling are required for collagen-induced DDR1 receptor activation and normal mammary cell adhesion. Int J Cancer 103: 344-351

Ferri N, Carragher NO, Raines EW (2004) Role of discoidin domain receptors 1 and 2 in human smooth muscle cell-mediated collagen remodeling: potential implications in atherosclerosis and lymphangioleiomyomatosis. Am J Pathol 164: 1575-1585

Glover TW, Arlt MF, Casper AM, Durkin SG (2005) Mechanisms of fragile site instability. Human Molecular Genetics 14: R197-R205
This is the first study to show a strong association of the collagen binding RTK, DDR1 with human lung cancer. We have conclusively shown that DDR1 is significantly more (2.15-fold) expressed in tumour as opposed to normal tissues from lung cancer patients, and have demonstrated that it can also be a strong prognostic indicator. Further research is required into the mechanisms by which both DDR1 and DDR2 function in lung carcinogenesis.

\section{ACKNOWLEDGEMENTS}

This work was supported by grants from the Swedish Foundation for International Cooperation in Research and Higher Education (TA, WV), the Swedish Cancer Association (TA), the National Cancer Institute of Canada (\#015184) (MST), the Canada Research Chair Program (WV) and the Premier's Research Excellence Award (WV). MST holds the Qasim M Choksi Chair in Lung Cancer Translational Research at Princess Margaret Hospital.

We wish to acknowledge Ni Liu and Davina Lau for technical assistance, and Dr Frances Shepherd for ongoing support.

Supplementary Information accompanies the paper on British Journal of Cancer website (http://www.nature.com/bjc)

Heinzelmann-Schwarz VA, Gardiner-Garden M, Henshall SM, Scurry J, Scolyer RA, Davies MJ, Heinzelmann M, Kalish LH, Bali A, Kench JG, Edwards LS, Vanden Bergh PM, Hacker NF, Sutherland RL, O'Brien PM (2004) Overexpression of the cell adhesion molecules DDR1, Claudin 3, and Ep-CAM in metaplastic ovarian epithelium and ovarian cancer. Clin Cancer Res 10: $4427-4436$

Hou G, Vogel W, Bendeck MP (2001) The discoidin domain receptor tyrosine kinase DDR1 in arterial wound repair. J Clin Invest 107: 727 735

Hou G, Vogel WF, Bendeck MP (2002) Tyrosine kinase activity of discoidin domain receptor 1 is necessary for smooth muscle cell migration and matrix metalloproteinase expression. Circ Res 90: 1147-1149

Johnson JD, Edman JC, Rutter WJ (1993) A receptor tyrosine kinase found in breast carcinoma cells has an extracellular discoidin I-like domain. Proc Natl Acad Sci USA 90: 5677-5681

Lee R, Eidman KE, Kren SM, Hostetter TH, Segal Y (2004) Localization of discoidin domain receptors in rat kidney. Nephron Exp Nephrol 97: $\mathrm{e} 62-\mathrm{e} 70$

Liu C, Tsao MS (1993) Proto-oncogene and growth factor/receptor expression in the establishment of primary human non-small cell lung carcinoma cell lines. Am J Pathol 142: 413-423

Mao TK, Kimura Y, Kenny TP, Branchi A, Gishi RG, Van de Water J, Kung HJ, Friedman SL, Gershwin ME (2002) Elevated expression of tyrosine kinase DDR2 in primary biliary cirrhosis. Autoimmunity 35: 521-529

Matsuyama W, Watanabe M, Shirahama Y, Hirano R, Mitsuyama H, Higashimoto I, Osame M, Arimura K (2006a) Suppression of discoidin domain receptor 1 by RNA interference attenuates lung inflammation. J Immunol 176: 1928-1936

Matsuyama W, Watanabe M, Shirahama Y, Mitsuyama H, Higashimoto I, Osame M, Arimura K (2006b) Discoidin domain receptor 1 contributes to the survival of lung fibroblast in idiopathic pulmonary fibrosis. Am J Pathol 168: $866-877$

Nemoto T, Ohashi K, Akashi T, Johnson JD, Hirokawa K (1997) Overexpression of protein tyrosine kinases in human esophageal cancer. Pathobiology 65: 195-203

Ongusaha PP, Kim JI, Fang L, Wong TW, Yancopoulos GD, Aaronson SA, Lee SW (2003) p53 induction and activation of DDR1 kinase counteract p53-mediated apoptosis and influence p53 regulation through a positive feedback loop. EMBO J 22: 1289-1301

Ram R, Lorente G, Nikolich K, Urfer R, Foehr E, Nagavarapu U (2006) Discoidin domain receptor-1a (DDR1a) promotes glioma cell invasion 
and adhesion in association with matrix metalloproteinase-2. I Neurooncol 76: $239-248$

Sakurada A, Shepherd FA, Tsao MS (2006) Epidermal growth factor receptor tyrosine kinase inhibitors in lung cancer: impact of primary or secondary mutations. Clin Lung Cancer 7(Suppl 4): S138-S144

Shepherd FA, Rodrigues Pereira J, Ciuleanu T, Tan EH, Hirsh V, Thongprasert S, Campos D, Maoleekoonpiroj S, Smylie M, Martins R, van Kooten M, Dediu M, Findlay B, Tu D, Johnston D, Bezjak A, Clark G, Santabarbara P, Seymour L (2005) Erlotinib in previously treated nonsmall-cell lung cancer. $N$ Engl J Med 353: 123 - 132

Shigematsu H, Gazdar AF (2006) Somatic mutations of epidermal growth factor receptor signaling pathway in lung cancers. Int $J$ Cancer 118: $257-262$
Tsao MS, Sakurada A, Cutz JC, Zhu CQ, Kamel-Reid S, Squire J, Lorimer I, Zhang T, Liu N, Daneshmand M, Marrano P, da Cunha Santos G, Lagarde A, Richardson F, Seymour L, Whitehead M, Ding K, Pater J, Shepherd FA (2005) Erlotinib in lung cancer - molecular and clinical predictors of outcome. $N$ Engl J Med 353: 133 - 144

Vogel WF, Abdulhussein R, Ford CE (2006) Sensing extracellular matrix: an update on discoidin domain receptor function. Cell Signal 18: 1108-1116

Weiner HL, Huang H, Zagzag D, Boyce H, Lichtenbaum R, Ziff EB (2000) Consistent and selective expression of the discoidin domain receptor-1 tyrosine kinase in human brain tumors. Neurosurgery 47: 1400-1409

Yun JJ, Heisler LE, Hwang IIL, Wilkins O, Lau SK, Hyrcza M, Jayabalasingham B, Jin J, McLaurin J, Tsao M-S, Der SD (2006) Genomic DNA functions as a universal external standard in quantitative real-time PCR. Nucl Acids Res 34(12): e85 